\title{
PENGARUH CITRA MEREK TERHADAP KEPUTUSAN PEMBELIAN PADA PT. ASTRA INTERNATIONAL, TbK TOYOTA AUTO 2000
}

\author{
Cornelia Dumarya Manik ${ }^{1)^{*}}$ \\ ${ }^{1)}$ Universitas Pamulang
}

*Penulis Korespondensi: cornelia00720@unpam.ac.id

\begin{abstract}
Penelitian ini bertujuan untuk mengetahui seberapa besar pengaruh citra merek terhadap keputusan pembelian pada PT. Astra International, Tbk-Toyota Auto 2000 cabang Bumi Serpong Damai. Penelitian ini dilaksanakan di PT. Astra International, Tbk-Toyota Auto 2000 cabang Bumi Srpong Damai. Model penelitian yang digunakan yakni dengan metode observasi, wawancara, kuesioner dan studi kepustakaan yang dilakukan secara sistematik berdasarkan tujuan penelitian. Metode penelitian ini menggunakan metode kuantitatif, asosiatif dengan populasi dalam penelitian ini adalah pelanggan yang melakukan service berkala pada PT. Astra International, Tbk-Toyota Auto 2000 cabang Bumi Serpong Damai, dalam waktu 5 (lima) tahun yaitu sebanyak 624 pelanggan. Metode penarikan sampel menggunakan rumus Slovin didapat sebanyak 86 responden. Metode analisis dalam pengolahan data adalah uji validitas dan reliabilitas, uji regresi linear sederhana, koefisien determinasi, uji hipotesis (uji-t), dan uji korelasi pearson product moment untuk mengetahui seberapa besar pengaruh citra merek terhadap keputusan pembelian mobil Toyota Yaris.
\end{abstract}

Keywords: Citra merek, Keputusan Pembelian. 


\section{PENDAHULUAN}

Pertumbuhan ekonomi yang semakin pesat memberikan dampak pada kesibukan aktifitas sehari-hari baik perorangan, perusahaan atau organisasi sehingga dibutuhkan sebuah alat transportasi yang memadai agar segala kegiatan dapat berjalan sesuai dengan rencana, dan tujuan yang akan dicapai dapat terlaksana dengan cepat, akurat, lancar dan efisien baik dari segi waktu maupun biaya,salah satu alat penunjang aktifitas tersebut adalah kendaraan beroda empat atau lebih (mobil), untuk menunjang kelancaran aktifitas perorangan atau perusahaan dibutuhkan mobil yang handal, irit dan memiliki multi purpose (multi guna). Mobil yang dimiliki oleh perorangan atau perusahaan merupakan suatu bentuk asset yang berwujud yang harus selalu dijaga atau dirawat supaya berguna dalam menunjang aktifitas sehari-hari dan memiliki nilai jual yang tinggi,untuk menjaga supaya kondisi mobil tetap optimal, pemilik harus melakukan perawatan yaitu dengan melakukan service secara berkala, pemilik harus cermat dalam memilih tempat service kendaraan dan tidak boleh sembarangan, karena hasil dari service kendaraan sangat menentukan umur kendaraan dan biaya yang dikeluarkan serta garansi atas perbaikan, jika hal tersebut tidak diperhatikan dapat menimbulkan kerugian yang besar biaya yang besar dan kendaraan tidak dapat digunakan secara optimal.

Produk industri otomotif sangat kompetitif dalam bentuk, warna, kecanggihan teknologi dan merek. Merek-merek mobil yang ada dipasaran otomotif di Indonesia sekarang ini berasal dari buatan Eropa dan Asia seperti Mitsubishi, KIA, Honda, Daihatsu, Suzuki, Ford, Proton, Nissan, Hyundai, dan Toyota yang banyak diminati oleh masyarakat Indonesia. setiap merek produk menawarkan pelayanan tersendiri untuk pelanggannya, berupa layanan purna jual, servis, suku cadang, sampai penetapan harga yang cukup bersaing sesuai dengan jenis dan segmen pasarnya, pilihan perusahaan untuk tetap eksis, yaitu dengan meningkatkan kualitas produk dan pelayanan, tidak hanya itu perusahaan harus mempunyai strategi dalam pemasaran produk antara lain brand image (citra merk).

Dengan adanya dua kriteria tersebut tidak menutup kemungkinan dalam satu kategori produk terdapat lebih dari satu merek - maksimal tiga merek yang meraih predikat Top Brand. Honda Jazz, Toyota Yaris, Suzuki Swift, KIA Picanto, Suzuki Karimun, dan Daihatsu Alya sebagai mobil segmen City Car yang mendominasi penjualan mobil segmen City Car di Indonesia. Honda Jazz dimana dalam tiga tahun terakhir ini selalu berhasil meraih predikat Top Brand tertinggi di bandingkan dengan Suzuki Swift, KIA Picanto, Suzuki Karimun, dan Daihatsu Alya.

Tabel 1Data Penjualan Mobil Yaris 2013-2017

\begin{tabular}{|l|l|l|l|l|l|}
\hline \multirow{2}{*}{ MEREK MOBIL } & \multicolumn{5}{|c|}{ TAHUN / UNIT } \\
\cline { 2 - 6 } & 2013 & 2014 & 2015 & 2016 & 2017 \\
\hline Toyata Yaris & $\underline{51}$ & $\underline{182}$ & $\underline{185}$ & $\underline{125}$ & $\underline{81}$ \\
\hline
\end{tabular}

Sumber : Toyota Dealer Management SystemAUTO 2000 BSD

Namun tidak demikian dengan Toyota Yaris pada tahun 2016 menurun, hal ini menunjukan bahwa minat konsumen untuk membeli Toyota Yaris cenderung turun, penyebabnya adalah bensin boros, kadang kurang tenaga saat melewati tanjakan, suspensi keras, tarikan kurang responsif dan trend pemakain mobil City Car bergeser ke mobil yang harganya lebih murah. Auto 2000 memanfaatkan event ini untuk melakukan berbagai perbaikan di intern perusahaan,meningkatkan kepuasan pelanggan dan event ini merupakan suatu cara untuk mengukuhkan Top Brand Toyota dan menguatkan merek Toyota menjadi lebih dikenal oleh masyarakat luas, bahkan untuk menarik segmen-segmen yang lain. Berdasarkan permasalahan diatas, peneliti memilih melakukan penelitian pada PT.Astra International Tbk-Toyota Auto 2000 Bumi Serpong Damai yang terletak di BSD Komersial VII C No.2 \& 2A Serpong Tangerang, menyadari pentingnya layanan purna jual untuk memberikan kepuasan pelanggan, meningkatkan loyalitas pelanggan Toyota dan meningkatkan citra merek Toyota serta meningkatkan minat pembelian maka hal tersebut menjadi daya tarik sendiri bagi peneliti untuk meneliti tanggapan konsumen terhadap citra merek dan kualitas pelayanan bagian service dalam mendukung penjualan kendaraan mobil merk Toyota, untuk itu penulis mencoba menelitinya dalam bentuk skripsi yang berjudul "Pangaruh Citra Merek Terhadap Keputusan Pembelian Mobil Toyota 
Yaris Pada PT. Astra International, TbkToyota AUTO 2000 Bumi Serpong Damai’.

\section{TINJAUAN PUSTAKA}

Brand image (citra merk) menurut Hermawan Kartajaya bukan hanya logo atau simbol sebuah produk melainkan value yang ditawarkan perusahaan kepada pelanggan. Merk merupakan aset yang menciptakan value bagi pelanggan dengan memperkuat kepuasan dan loyalitasnya.

Merk merupakan hasil dari setiap langkah-langkah (strategi) yang dilakukan perusahaan dalam membangun dan mengembangkan produk. Suatu merk dikatakan memiliki value yang tinggi apabila merk tersebut memberikan rasio yang tinggi kepada pelanggan antara total get dan total give. Total get terdiri dari dua unsur yaitu functional benefit dan emotional benefit, sementara total give mencakup unsur-unsur price dan other expenses. Functional benefit, yaitu terkait dengan fungsi atau manfaat atas suatu produk. Emotional benefit, yaitu manfaat yang dirasakan konsumen berupa stimulasi terhadap emosi dan perasaannya. Price, adalah biaya yang dikeluarkan konsumen untuk memperoleh barang (merk). Other expenses, adalah biaya yang dikeluarkan konsumen selama menggunakan atau mengkonsumsi produk (merk) tersebut.

Keputusan untuk membeli suatu produk sangat dipengaruhi oleh penilaian akan kualitas produk tersebut. Tuntutan permintaan akan sebuah produk barang yang semakin berkualitas membuat perusahaan yang bergerak diberbagai bidang usaha berlombalomba meningkatkan kualitas produk yang mereka miliki demi mempertahankan brand image (citra merek) produk yang mereka miliki. Merek mempunyai sifat khas, dan sifat khas inilah yang membedakan produk yang satu berbeda dengan produk yang lainnya.

Keputusan pembelian oleh konsumen adalah keputusan yang melibatkan persepsi terhadap kualitas, nilai, dan harga. Konsumen tidak hanya menggunakan harga sebagai indikator kualitas, tetapi juga sebagai indikator biaya yang dikeluarkan untuk ditukar dengan model produk atau manfaat produk. Karenanya, melihat sejauh mana merek yang disandangkan dapat memengaruhi penilaian konsumen terhadap brand image (citra merek) dari produk tersebut.
Berbagai upaya dilakukan perusahaan dalam rangka mempertahankan brand image yang mereka miliki diantaranya inovasi teknologi keunggulan yang dimiliki produk tersebut, penetapan harga yang bersaing, dan promosi yang tepat sasaran. Semakin baik Brand Image produk yang dijual, maka semakin tinggi keputusan pembelian oleh konsumen.

Salah satu survei merek di Indonesia yang dijadikan sebagai indikator kinerja sebuah merek adalah Top Brand Award. Survei ini dipelopori oleh majalah "MARKETING" yang bekerja sama dengan lembaga survei Frontier Consulting Group. Konsep tentang Top Brand mengenai merek suatu produk didasarkan pada tiga parameter yaitu: merek yang paling diingat (top of mind), merek yang terakhir kali dibeli atau dikonsumsi (last used), serta merek yang akan dipilih kembali di masa mendatang (future intention). Ketiga parameter tersebut diformulasikan dengan cara menghitung ratarata terboboti masing-masing parameter untuk membentuk Top Brand Index (TBI). Kriteria yang harus dipenuhi agar sebuah merek berhak menyandang predikat Top Brand adalah memperoleh Top Brand Index minimum sebesar $10 \%$ dan berada dalam posisi top three di dalam kategori produknya.

\section{METODE PENELITIAN}

Populasi dalam penelitian ini sebanyak 624 pelanggan BSD Komersial VII C No.2 \& 2A Serpong Tangerang. Teknik pengambilan sampling dalam penelitian ini adalah menggunakan rumus Slovin, dimana semua anggota populasi dijadikan sebagai sampel. Dengan demikian sampel dalam penelitian ini sampel yang digunakan berjumlah 86. Sifat penelitian ini merupakan penelitian diskriptif kuantitatif. Maksudnya yaitu yaitu penelitian tentang data yang dikumpulkan dan dinyatakan dalam bentuk angka-angka, meskipun juga berupa data kualitatif sebagai pendukungnya, seperti kata-kata atau kalimat yang tersusun dalam angket, kalimat hasil konsultasi atau wawancara antara peneliti dan informan. Dalam menganalisis data digunakan uji validitas, uji reliabilitas, analisis regresi linier sederhana, analisis koefisien korelasi, analisis koefisien determinasi. 


\section{HASIL DAN PEMBAHASAN}

Uji Validitas

Uji Validitas Citra Merek (X)

Tabel 2. Perhitungan Uji Validitas Variabel

Citra Merek

\begin{tabular}{|c|c|c|c|}
\hline Item Kuesioner & $\begin{array}{l}\text { Nilai } \\
\text { r hitung }\end{array}$ & $\begin{array}{l}\text { Nilai } \\
\text { r table }\end{array}$ & Keputusan \\
\hline $\begin{array}{l}\text { Toyota Yaris memiliki } \\
\text { pilihan type sesuai } \\
\text { dengan kebutuhan } \\
\text { masyarakat }\end{array}$ & 0,524 & 0,212 & Valid \\
\hline $\begin{array}{l}\text { Kelengkapan fitur } \\
\text { yang dimiliki Toyota } \\
\text { Yaris sangat optimal }\end{array}$ & 0,439 & 0,212 & Valid \\
\hline $\begin{array}{l}\text { Toyota Yaris } \\
\text { menggunakan } \\
\text { teknologi dan inovasi } \\
\text { yang canggih }\end{array}$ & 0,228 & 0,212 & Valid \\
\hline $\begin{array}{lr}\text { Harga } & \text { Toyota } \begin{array}{r}\text { Yaris } \\
\text { sesuai }\end{array} \\
\text { kualitasnya } & \text { dengan } \\
\end{array}$ & 0,427 & 0,212 & Valid \\
\hline $\begin{array}{l}\text { Toyota Yaris mudah } \\
\text { diingat dan diucapkan }\end{array}$ & 0,409 & 0,212 & Valid \\
\hline $\begin{array}{lr}\text { Toyota } & \text { Yaris } \\
\text { diproduksi } & \text { oleh } \\
\text { perusahaan } & \text { yang } \\
\text { memiliki } & \text { kredibilitas } \\
\text { tinggi } & \\
\end{array}$ & 0,567 & 0,212 & Valid \\
\hline $\begin{array}{l}\text { Kemudahan } \\
\text { mendapatkan spare } \\
\text { parts Toyota Yaris }\end{array}$ & 0,360 & 0,212 & Valid \\
\hline $\begin{array}{lr}\begin{array}{l}\text { Kemudahan } \\
\text { perawatan } \\
\text { perbaikan }\end{array} & \begin{array}{r}\text { dalam } \\
\text { dan }\end{array} \\
\end{array}$ & 0,508 & 0,212 & Valid \\
\hline $\begin{array}{l}\text { Proses waranty mudah } \\
\text { dan cepat }\end{array}$ & 0,220 & 0,212 & Valid \\
\hline $\begin{array}{l}\text { Harga purna jual yang } \\
\text { stabil }\end{array}$ & 0,535 & 0,212 & Valid \\
\hline
\end{tabular}

Sumber : Data primer hasil pengolahan SPSS versi 22 (2018)

Berdasarkan tabel 4.6 di atas, semua item pernyataan variabel citra merek berada di atas angka 0,212 atau ( $\left.\mathrm{r}_{\text {hitung }}>\mathrm{r}_{\text {tabel }}\right)$, maka semua item dinyatakan valid. Untuk itu kuesioner yang digunakan layak untuk diolah sebagai data penelitian.

Uji Validitas Keputusan Pembelian (Y)

Tabel 3. Perhitungan Uji Validitas Variabel Keputusan Pembelian

\begin{tabular}{|l|l|l|l|}
\hline Item Kuesioner & $\begin{array}{l}\text { Nilai } \\
\text { r hitung }\end{array}$ & $\begin{array}{l}\text { Nilai } \\
\text { r tabel }\end{array}$ & Keputusan \\
\hline $\begin{array}{l}\text { Saya membeli Toyota } \\
\text { Yaris karena kebutuhan } \\
\text { untuk transportasi }\end{array}$ & 0,509 & 0,212 & Valid \\
\hline $\begin{array}{l}\text { Saya memilih Toyota } \\
\text { Yaris karena banyak } \\
\text { teman yang memakainya }\end{array}$ & 0,424 & 0,212 & Valid \\
\hline $\begin{array}{l}\text { Saya memilih Toyota } \\
\text { Yaris karena banyak } \\
\text { keluarga yang } \\
\text { memakainya }\end{array}$ & 0,474 & 0,212 & Valid \\
\hline $\begin{array}{l}\text { Saya memilih Toyota } \\
\text { Yaris karena masyarakat } \\
\text { banyak memakainya }\end{array}$ & 0,545 & 0,212 & Valid \\
\hline $\begin{array}{l}\text { Saya mendapatkan } \\
\text { informasi produk Toyota } \\
\text { Yaris melalui browsing }\end{array}$ & 0,479 & 0,212 & Valid \\
\hline
\end{tabular}

\begin{tabular}{|l|l|l|l|}
\hline Item Kuesioner & $\begin{array}{l}\text { Nilai } \\
\text { r hitung }\end{array}$ & $\begin{array}{l}\text { Nilai } \\
\text { r tabel }\end{array}$ & Keputusan \\
\hline internet & & & \\
\hline $\begin{array}{l}\text { Saya memilih Toyota } \\
\text { Yaris karena nyaman } \\
\text { ketika mengendarai }\end{array}$ & 0,304 & 0,212 & Valid \\
\hline $\begin{array}{l}\text { Saya memilih Toyota } \\
\text { Yaris karena Toyota } \\
\text { yaris dikenal masyarakat } \\
\text { banyak }\end{array}$ & 0,290 & 0,212 & Valid \\
\hline $\begin{array}{l}\text { Jika saya service di Auto } \\
\text { 2000 saya merasa puas }\end{array}$ & 0,456 & 0,212 & Valid \\
\hline $\begin{array}{l}\text { Kendaraan yang telah di } \\
\text { service terjamin hasilnya }\end{array}$ & 0,228 & 0,212 & Valid \\
\hline $\begin{array}{l}\text { Saya merasa puas } \\
\text { setelah membeli Toyota } \\
\text { Yaris dan } \\
\text { merekomendasikan } \\
\text { cerita positif tentang } \\
\text { Toyota Yaris }\end{array}$ & 0,287 & 0,212 & Valid \\
\hline
\end{tabular}

Sumber : Data primer hasil pengolahan SPSS versi 22 (2018)

Berdasarkan tabel 4.7 di atas, semua item pernyataan variabel keputusan pembelian berada di atas angka 0,212 atau ( $r_{\text {hitung }}>r_{\text {tabel }}$ ), maka semua item dinyatakan valid. Untuk itu kuesioner yang digunakan layak untuk diolah sebagai data penelitian.

Analisis Verifikatif.

Pada analisis ini dimaksudkan untuk mengetahui pengaruh variabel independen terhadap variabel dependen. Adapun hasil pengujian sebagai berikut:

Uji regresi ini dimaksudkan untuk mengetahui seberapa besar pengaruh kualitas pelayanan terhadap kepuasan pelanggan. Sebelum dilakukan uji regresi, maka terlebih dahulu akan disajikan hasil olahan data regresi dengan menggunakan program SPSS versi 22 yang dapat dilihat pada tabel berikut ini :

Tabel 4. Hasil Pengolahan Data Regresi Linier Sederhana

\begin{tabular}{|c|c|c|c|c|c|c|}
\hline \multicolumn{7}{|c|}{ Coefficients $^{a}$} \\
\hline \multirow{2}{*}{\multicolumn{2}{|c|}{ Model }} & \multicolumn{2}{|c|}{\begin{tabular}{|l} 
Unstandardized \\
Coefficients
\end{tabular}} & \multirow{2}{*}{\begin{tabular}{|l}
$\begin{array}{l}\text { Standardized } \\
\text { Coefficients }\end{array}$ \\
Beta
\end{tabular}} & \multirow[b]{2}{*}{$T$} & \multirow[b]{2}{*}{ Sig. } \\
\hline & & $B$ & \begin{tabular}{|l} 
Std. \\
Error
\end{tabular} & & & \\
\hline \multirow[t]{2}{*}{1} & (Constant) & 16.546 & 3.438 & & 4.813 & .000 \\
\hline & Citra Merek & .583 & .084 & .602 & 6.907 & .000 \\
\hline
\end{tabular}

Sumber : Data primer hasil pengolahan SPSS versi 22 (2018)

Analisis Koefisien Korelasi

Analisa koefisien korelasi dimaksudkan untuk mengetahui tingkat hubungan antar variabel. 
Adapun hasil pengolahan data dengan program SPSS versi 22, yaitu sebagai berikut :

Tabel 5. Hasil Pengolahan Data Koefisien Korelasi Product Moment

\begin{tabular}{|c|c|c|c|c|}
\hline \multicolumn{5}{|c|}{ Model Summary } \\
\hline Model & $R$ & $\begin{array}{l}R \\
\text { Square }\end{array}$ & $\begin{array}{l}\text { Adjusted } \\
\text { Square }\end{array}$ & $\begin{array}{l}\text { Std. Error } \\
R \text { of the } \\
\text { Estimate }\end{array}$ \\
\hline 1 & $.602^{\mathrm{a}}$ & .362 & .355 & 2.258 \\
\hline
\end{tabular}

Sumber : Data primer hasil pengolahan SPSS versi 22 (2018)

Tabel 6. Pedoman Interpretasi Koefisien Korelasi

\begin{tabular}{|l|l|}
\hline $\begin{array}{l}\text { Interval Nilai Koefisien } \\
\text { Korelasi }\end{array}$ & $\begin{array}{l}\text { Tingkat } \\
\text { Hubungan }\end{array}$ \\
\hline $0,000-0,199$ & Sangat rendah \\
\hline $0,200-0,399$ & Rendah \\
\hline $0,400-0,599$ & Cukup Kuat \\
\hline $0,600-0,799$ & Kuat \\
\hline $0,800-1,000$ & Sangat kuat \\
\hline
\end{tabular}

Sumber : Sugiyono (2016:184)

Berdasarkan hasil perhitungan pada tabel 4.12 di atas diperoleh koefisien korelasi (r) nya sebesar 0,602

Analisis Koefisien Determinasi

Analisis koefisien determinasi dimaksudkan untuk mengetahui besarnya persentase pengaruh dari variabel independen terhadap variabel dependen.

Tabel 7. Hasil Pengolahan Data Koefisien Determinasi (KD)

\begin{tabular}{|l|l|l|l|l|}
\hline Model Summary \\
\hline Model & $\mathbf{R}$ & $\begin{array}{l}\text { R } \\
\text { Square }\end{array}$ & $\begin{array}{l}\text { Adjusted R R } \\
\text { Square }\end{array}$ & $\begin{array}{l}\text { Std. Error } \\
\text { Estimate }\end{array}$ \\
\hline 1 & $1602^{\mathrm{a}}$ & .362 & .355 & 2.258 \\
\hline \multicolumn{2}{|l|}{ a. Predictors: (Constant), Citra Merek } \\
\hline
\end{tabular}

Sumber : Data primer hasil pengolahan SPSS versi 22 (2018)

Berdasarkan hasil perhitungan pada tabel 4.14 diatas, diperoleh nilai koefisien determinasi 0,362, maka dapat disimpulkan bahwa citra merek $(\mathrm{X})$ berpengaruh terhadap keputusan pembelian (Y) sebesar 36,2\% sedangkan sisanya sebesar $63,8 \%$ dipengaruhi oleh faktor lain.

\section{Uji Hipotesis}

Tabel 8. Hasil Pengolahan Data Pengujian Hipotesis/Uji t

Coefficients $^{a}$

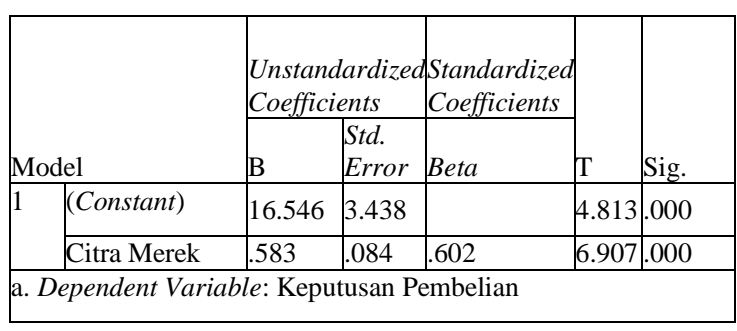

Sumber : Data primer hasil pengolahan SPSS versi 22 (2018)

Berdasarkan perhitungan pada tabel 4.15 di atas diperoleh nilai $\mathrm{t}_{\text {hitung }}>\mathrm{t}_{\text {tabel }}$ atau $(6,907>$ 1,9886), hal ini juga diperkuat dengan nilai signifikansi $0,000<0,05$, maka dapat dikatakan signifikan. Artinya $\mathrm{H}_{\mathrm{o}}$ ditolak dan $\mathrm{H}_{1}$ diterima, berarti terdapat pengaruh yang positif dan signifikan antara citra merek terhadap keputusan pembelian.

\section{Pembahasan}

Citra Merek masih di persepsikan baik (B). Hal itu dapat di lihat dari rata-rata nilai score 3,50 ada pada interval 3,40-4,19 dengan interprestasi Baik. Kondisi Jawaban Responden Variabel. Keputusan Pembelian masih di persepsikan baik (B). Hal itu dapat di lihat dari rata-rata nilai score 3,47 ada pada interval 3,40-4,19 dengan interprestasi Baik. Terdapat pengaruh positif yang Kuat dan signifikan antara Citra Merek terhadap Keputusan Pembelian dengan nilai regresi sebesar 0,583. Nilai koefisien korelasi (r) sebesar 0,602 dan nilai determinasi (Kd) sebesar 0,362 atau $36,2 \%$ sedangkan sisanya sebesar $63,8 \%$ dipengaruhi oleh faktor lain. Pengujian hipotesis menggunakan uji statistik $\mathrm{t}$ hitung diperoleh $\mathrm{t}_{\text {hitung }}>\mathrm{t}_{\text {tabel }}(6,907>1,9886)$, hal ini juga diperkuat dengan nilai signifikansi $0,000<0,05$, maka dapat dikatakan signifikan. Dengan demikian $\mathrm{H}_{0}$ ditolak dan $\mathrm{H}_{1}$ diterima artinya terdapat pengaruh yang positif dan signifikan antara Citra Merek terhadap Keputusan Pembelian. Hal ini sesuai dengan penelitian yang dilakukan oleh Danny Alexander Bastian dalam Jurnal Manajemen Pemasaran Petra yang mengemukakan bahwa Variabel brand image berpengaruh positif signifikan terhadap brand loyalty. Hal ini menunjukkan citra merek yang dibentuk karena perusahaan mampu memberikan presepsi yang baik kepada konsumennya dan juga menjaga dan mengelola hubungan dengan konsumen ADES 


\section{KESIMPULAN DAN SARAN}

Citra Merek masih di persepsikan baik. Citra Merek berpengaruh terhadap keputusan pembelian mobil Toyota Yaris pada PT.Astra International Tbk-Toyota Auto 2000 Bumi Serpong Damai. Dimana dapat dilihat bahwa dengan adanya peningkatan Citra Merek akan selalu diikuti oleh keputusan pembelian.

Keputusan Pembelian masih di persepsikan baik (B). Terdapat pengaruh antara citra merek dengan keputusan pembelian mobil Toyota Yaris pada PT. Astra International Tbk-Toyota Auto 2000 Bumi Serpong Damai. Terdapat pengaruh positif yang Kuat dan signifikan antara Citra Merek terhadap Keputusan Pembelian.

\section{Saran}

Berdasarkan hasil penelitian dan kesimpulan diatas, maka saran yang dapat penulis sampaikan sebagai berikut. Pihak perusahaan sebagai penyedia produk harus memiliki pilihan type sesuai dengan kebutuhan masyarakat dan harus terus meningkatkan kualitas produk yang dihasilkan demi terpenuhinya harapan konsumen, dan konsumen merasa bahwa type produk yang dikeluarkan hasilnya sesuai dengan apa yang diharapkan. Sehingga tercipta loyalitas konsumen yang dapat memberikan dampak terhadap pembelian. Toyota perlu memfokuskan kebijakan pemasarannya pada harga purna jual yang stabil sehingga dapat berusaha untuk mempertahankan atau memelihara serta meningkatkan kekuatan asosiasi merek mobil Toyota Yaris. Meningkatkan teknologi dan inovasi, serta menyediakan suku cadang yang mudah diperoleh perlu dilakukan oleh pihak perusahaan dalam meningkatkan kekuatan asosiasi merek. Pihak Toyota juga perlu menaruh perhatian lebih pada keunggulan asosiasi mereknya dengan menambah persepsi nilai yang positif kepada konsumen terutama pada peningkatan kualitas model serta menambah variasi dari mobil Toyota Yaris tanpa melupakan kualitas kenyamanan. Karena kini telah banyak bermunculan merek-merek pesaing yang menawarkan produknya dengan model-model yang bervariasi. Oleh karena itu, Toyota perlu menanamkan persepsi positif di benak pelanggan bahwa Mobil Toyota Yaris banyak digunakan oleh masyarakat dan mobil
Toyota Yaris adalah mobil dengan kualitas model yang tak kalah dari merek pesaingnya tanpa melupakan kualitas kenyamanan.

\section{REFERENSI}

Ade Trisno. 2016. "Pengaruh Citra Merek Terhadap Pengambilan

Alma, Buchari, 2007. Manajemen dan Pemasaran Jasa, Penerbit PT. Alfabeta, Cetakan Kesembilan, Bandung.

Ardana. 2012. Manajemen Sumber Daya Manusia. Yogyakarta: Graha Ilmu Daryanto. 2011. Sari Kuliah Manajemen Pemasaran, Bandung: PT. Sarana

Effendy, A., \& Sunarsi, D. 2020. Persepsi Mahasiswa Terhadap Kemampuan Dalam Mendirikan UMKM Dan Efektivitas Promosi Melalui Online Di Kota Tangerang Selatan. Jurnal Ilmiah MEA (Manajemen, Ekonomi, \& Akuntansi), 4(3), 702-714. https://doi.org/10.31955/mea.v ol4.iss3.pp702-714

Ferinda dewi, Erna. 2008. Merek dan Psikologi Konsumen, Implikasi pada Strategi Pemasaran. Yogyakarta: Graha Ilmu.

Hasan, Misbahudin Iqbal. 2013. Analisis Data Penelitian Dengan Statistik. Jakarta: PT. Bumi Aksara

Kotler. 2009. Manajemen Pemasaran. Jilid 1, Edisi ketigabelas, Erlangga, Jakarta.

Purwanto, A., Sunarsi, D., \& Wijoyo, H. 2020. Penerapan Perluasan Arti Perbuatan Melanggar Hukum Dalam Pelaksanaan UU 29 Tahun 2004 (Studi Kasus Putusan No. 625/PDT. G/2014/PN JKT. BRT). TIN: Terapan Informatika Nusantara, 1(2), 99103.

Rizki Nurafdal Mustikarillah. 2011. "Pengaruh Brand Image Terhadap Pengambilan Keputusan Pembelian Mobil Toyota Rush pada PT. Hadji Kalla Makasar". Skripsi. Fakultas Ekonomi, Universitas Hasanuddin.

Sandy Setia Makruf. 2017. "Pengaruh Brand Image (Citra Merek), Harga

Sugiyono. 2013. Metode Penelitian Kuantitatif Kualitatif dan R\&D. Bandung : Alfabeta 
Sunarsi, D. 2018. Buku Ajar:Seminar Perencanaan Sumber Daya Manusia. Tangerang Selatan: Asmoro Mediatama

Sunarsi, D. 2018. Pengembangan Sumber Daya Manusia Strategik \& Karakterisrik Sistem Pendukungnya: Sebuah Tinjauan. Jurnal Ilmiah MEA (Manajemen, Ekonomi, \& Akuntansi), 2(3), $\quad 178$ 194. https://doi.org/10.31955/mea.v ol2.iss3.pp178 - 194

Sunarsi, D., Wijoyo, H., Prasada, D., \& Andi, D. 2020. Pengaruh Lingkungan Kerja Terhadap Kinerja Karyawan Pada PT. Mentari Persada Di Jakarta. In Seminar Nasional Manajemen, Ekonomi, Akuntansi (Vol. 5, No. 1, pp. 117-123). 